\title{
EXCHANGE RATE VOLATILITY AND RWANDA'S BALANCE OF TRADE
}

\section{Announcement of Retraction}

The editorial board announced this article has been retracted on April 27, 2017.

If you have any further question, please contact us at ijld@macrothink.org

Article Title: EXCHANGE RATE VOLATILITY AND RWANDA'S BALANCE OF TRADE Author/s: Maniragaba Ngabo Vallence \& Nkurunziza Fabrice

Journal Title: International Journal of Learning and Development

ISSN: $2164-4063$

Volume and Number: Vol. 6, No. 1, 2016

Pages: 104-135

Doi:10.5296/ ijld.v5i3.8945 